\section{Primary Sjogren's syndrome presenting as autoimmune cytopenia}

\author{
Durga Shankar Meena, \\ Gopal Krishana Bohra
}

Department of Medicine, All India Institute of Medical Sciences, Jodhpur, India

\begin{abstract}
Sjogren's syndrome (SS) is a chronic systemic autoimmune disease, characterized by lymphocytic infiltration of lacrimal and salivary glands. Although extra glandular manifestations are uncommon, they can occur with the musculoskeletal, renal, pulmonary and hematological disease. We report the case of a 35-year-old woman presented to us with persistent unexplained bicytopenia (anemia and thrombocytopenia). Antinuclear antibody and direct Coombs test were positive. Anti-Ro/SSA and anti-La/SSB antibodies were also positive in high titer. The final diagnosis of primary SS with autoimmune cytopenia was made. Cytopenias in SS are rarely reported. Our case illustrates that clinically significant cytopenias may present as an extraglandular manifestation of SS.
\end{abstract}

\section{Introduction}

Sjogren's syndrome (SS) is a systemic autoimmune disease characterized by dry eyes and dry mouth. Lymphocyte infiltration of salivary and lacrimal glands is the common feature of SS. Common extraglandular presentations of SS are arthralgia, gastrointestinal symptoms, peripheral neuropathy and renal disease. The hematological abnormalities in primary SS (pSS) are not infrequent. Anemia of chronic disease is the most common presentation. ${ }^{1}$ However, clinically significant cytopenias are uncommon in SS. Leukopenia is usually mild with differential white blood cell counts are mostly normal, which do not require hospitalization. Though, newly developed cytopenia in an established patient of SS can be a sign of developing lymphoma. The pathophysiology and prevalence of cytopenia in SS is still an area of ongoing research. Sometimes a patient can present with severe hemolytic anemia, leukopenia or thrombocytopenia prior to the development of sicca symptoms. Autoimmune cytopenia associated with SS is rarely described in the literature. We herein report a case of pSS presented as immune hemolytic anemia with thrombocytopenia.

\section{Case Report}

A 35-year-old woman presented to us with complaints of generalized weakness, increasing fatigue for last 1 year. There was no history of fever, rash, weight loss, diarrhea or pain abdomen. The patient was not suffering from any chronic illness in past. On general examination, lower palpebral conjunctiva was pale, mild icterus was also present. There was no lymphadenopathy. Spleen was palpable $3 \mathrm{~cm}$ below left costal margin. Rest systemic examination was unremarkable. Complete blood count revealed a hemoglobin level of $7.0 \mathrm{~g} / \mathrm{dL}$, white blood cell count (WBC) of $6.8 \times 10^{3} / \mu \mathrm{L}$ (differential: N $63 \%$, L 22\% M $13 \%$ ) and platelet count of $44 \times 10^{3} / \mu \mathrm{L}$. Biochemical analysis showed total protein $9.55 \mathrm{~g} / \mathrm{dL}$, albumin $2.95 \mathrm{~g} / \mathrm{dL}$, total bilirubin $2.1 \mathrm{mg} / \mathrm{dL}$, urea- $28 \mathrm{mg} / \mathrm{dL}$, creatinine $1.2 \mathrm{mg} / \mathrm{dL}$, sodium $135 \mathrm{mmol} / \mathrm{L}$ and potassium $3.46 \mathrm{mmol} / \mathrm{L}$. On further investigations, autoimmune profile revealed antinuclear antibodies positivity in high titer (1:1280, speckled). Anti-dsDNA antibodies were negative. In addition, Anti-Ro/SSA and Anti-La/SSB antibodies were also present in high titer. Peripheral blood film was suggestive of normocytic normochromic red blood cells (RBC) with few tear drop cells, serum Lactate dehydrogenase was $788 \mathrm{IU} / \mathrm{L}$. Bone marrow examination was normal. Both direct and indirect Coombs tests were positive. When asked specifically about sicca symptoms, our patient admitted having dry eyes and mouth for past few months. Ophthalmological examination showed a positive Schirmer's test $(2 \mathrm{~mm}$ in right and $3 \mathrm{~mm}$ left eye). Our patient fulfilled the diagnostic criteria (2016 ACREULAR Classification Criteria for pSS) for pSS. Based on these investigations, we made a final diagnosis of pSS with autoimmune bicytopenia.

The patient was put on oral prednisolone $(1 \mathrm{mg} / \mathrm{kg})$. After 1 month of follow-up, she was symptomatically improved with hemoglobin of $9.2 \mathrm{~g} / \mathrm{dL}, \mathrm{WBC}$ $6.6 \times 10^{3} / \mu \mathrm{L}$ and platelets count $110 \times 10^{3} / \mu$ L. At 3 months of follow-up, corticosteroid was tapered successfully with remission of hemolytic anemia and thrombocytopenia.

\section{Discussion}

$\mathrm{SS}$ is a multisystem autoimmune chron-
Correspondence: Durga Shankar Meena, Department of Medicine, All India Institute of Medical Sciences, Jodhpur 342003, India.

E-mail: dsmims14@gmail.com

Key words: Sjogren's syndrome; Coombs test; Cytopenia.

Contributions: the authors contributed equally.

Conflict of interest: the authors declare no potential conflict of interest.

Funding: none.

Received for publication: 9 August 2019.

Revision received: 25 October 2019

Accepted for publication: 25 October 2019

This work is licensed under a Creative Commons Attribution NonCommercial 4.0 License (CC BY-NC 4.0).

(C) Copyright: the Author(s), 2019

Licensee PAGEPress, Italy

Clinics and Practice 2019; 9:1190

doi:10.4081/cp.2019.1190

ic disorder, predominantly involving salivary and lacrimal glands. pSS is not associated with other diseases whereas secondary SS usually overlap other rheumatic disorders which include rheumatoid arthritis and systemic lupus erythematosus. Lymphocytes aggregation in salivary and lacrimal glands leads to xerostomia (dry mouth) and xerophthalmia (dry eyes) respectively in SS. Extra glandular involvement may occur, which include, musculoskeletal symptoms, vasculitis, pulmonary, renal, and hepatic disease and increased risk of lymphoma. Interstitial nephritis and tubular acidosis are the common renal manifestations in SS. ${ }^{2,3}$ Some of these systemic manifestations are due to autoimmune inflammation of ductal epithelial structures in various organs, like in interstitial nephritis. The hematological manifestations can occur with leukopenia is the most common cytopenia, reported in $15 \%$ of patients of $\mathrm{SS},{ }^{4}$ but clinically significant cytopenias requiring hospitalization, transfusion or immunosuppressant has been rarely reported in the literature. According to a report described by Ramakrishna et al., Coombs positivity can be a common feature of SS (22-47\%), but frank hemolysis is rare. ${ }^{4}$ There are case reports of pure red cell aplasia and immune-mediated thrombocytopenia with SS. ${ }^{5-8}$ According to $\mathrm{Yu}$ et al., pancytopenia can present as a complication of SS. ${ }^{9}$ Cytopenias may develop prior to typical sicca symptoms or as a sole presenting feature in SS (Table 1), which can delay the diagnosis of SS. ${ }^{6,8,9-13}$ Similar to these 
Table 1. Clinical and demographic characteristics of reported immune cytopenias in Sjogren's syndrome patients.

\begin{tabular}{|c|c|c|c|c|c|}
\hline Authors, Year of publication & Country & $\begin{array}{c}\text { Number of } \\
\text { cases }\end{array}$ & $\begin{array}{l}\text { Age/ } \\
\text { Gender }\end{array}$ & $\begin{array}{c}\text { Hematological } \\
\text { disease }\end{array}$ & Treatment \\
\hline Schattner et al. ${ }^{6}(2000)$ & Israel & 3 & $\begin{array}{l}32 \mathrm{yr} \text {, female } \\
77 \mathrm{yr} \text {, female } \\
58 \mathrm{yr} \text {, female }\end{array}$ & $\begin{array}{c}\text { Case 1. AIHA } \\
\text { Case 2. Neutropenia } \\
\text { Case 3. Thrombocytopenia }\end{array}$ & $\begin{array}{l}\text { Case 1. Corticosteroid/Azathioprine } \\
\text { Case 2. Corticosteroid } \\
\text { Case 3. Corticosteroid/cyclophosphamide }\end{array}$ \\
\hline Klepfish et al. ${ }^{10}(2001)$ & Israel & 1 & $40 \mathrm{yr}$, female & Neutropenia, thrombocytopenia & Asymptomatic, didn't receive immunosuppressant \\
\hline Kamath et al..$^{11}$ (2011) & India & 1 & $32 \mathrm{yr}$, female & Anemia and thrombocytopenia & Corticosteroid \\
\hline Khattri and Barland ${ }^{8}$ (2012) & USA & 2 & $\begin{array}{l}59 \mathrm{yr} \text {, female } \\
26 \mathrm{yr} \text {, female }\end{array}$ & $\begin{array}{l}\text { Case 1. AlHA with thrombocytopenia } \\
\text { Case 2. Thrombocytopenia }\end{array}$ & $\begin{array}{l}\text { Case 1. Corticosteroid/IVIG/Rituximab } \\
\text { Case 2. Corticosteroid//VIG }\end{array}$ \\
\hline Komaru et al. ${ }^{12}$ (2013) & Japan & 1 & $36 \mathrm{yr}$, female & AIHA & Corticosteroid/RBC transfusion \\
\hline Wenqing Yu et al. ${ }^{9}$ (2017) & China & 1 & $59 \mathrm{yr}$, female & Pancytopenia & Corticosteroid/VIG \\
\hline Martínez et al. ${ }^{13}$ (2018) & Colombia & 1 & $50 \mathrm{yr}$, female & Anemia and thrombocytopenia & Corticosteroid/Azathioprine \\
\hline
\end{tabular}

AIHA, Autoimmune hemolytic anemia; IVIG, intravenous immunoglobulin; RBC, red blood cells.

reports, our patient presented with thrombocytopenia and immune hemolytic anemia. Mild anemia usually occurs due to cytokine-mediated chronic inflammation however, the mechanism of hemolysis and bone marrow suppression in SS is still debatable. Immune-mediated thrombocytopenia, similar to systemic lupus erythematosus may be possible in SS. We speculate the presence of autoantibodies against different cell lineage is the triggering factor for cytopenias. According to some reports, antineutrophil and anti-RBC antibodies were observed in $45 \%$ and $22 \%$ of patients with SS respectively. ${ }^{5,14}$ Qing et al. hypothesized that deficient erythropoiesis in SS is attributed to the disorder of iron metabolism. ${ }^{15}$

Immunosuppressive therapy with corticosteroids is the treatment of choice for autoimmune cytopenias in SS Azathioprine, cyclophosphamide has been used in some cases in past with mixed response. ${ }^{16}$ The response of rituximab in immune cytopenias with SS was described by one report. ${ }^{8}$ Similar to its effect in immune thrombocytopenia, rituximab use was shown to improve cytopenia in the patients with SS.

\section{Conclusions}

As illustrated by our case, cytopenias may present prior to sicca symptoms in SS. Mild asymptomatic normocytic anemia is a frequent presentation, but as our case suggests, clinically significant hemolytic anemia and thrombocytopenia may present as occult pSS without predominant sicca symptoms. Although our patients improved with corticosteroids, long-term follow-up is needed to know more about the clinical course of hematological disease in these patients. SS should be considered as an important differential while evaluating unexplained cytopenias.

\section{References}

1. Zhou JG, Qing YF, Jiang L, et al. Clinical analysis of primary Sjogren's syndrome complicating anemia. Clin Rheumatol 2010;29:525-9.

2. Maripuri S, Grande JP, Osborn TG, et al. Renal involvement in primary Sjogren's syndrome: a clinicopathologic study. Clin J Am Soc Nephrol 2009;4: 1423.

3. Kidder D, Rutherford E, Kipgen D, et al. Kidney biopsy findings in primary Sjogren's syndrome. Nephrol Dial Transplant 2015;30:1363.

4. Ramakrishna R, Chaudhuri K, Sturgess A, Manoharan A. Haematological manifestations of primary Sjogren's syndrome: a clinicopathological study. Q J Med 1992;83:547-54.

5. Giordano N, Senesi M, Battisti E, et al. Sjogren's syndrome and pure red cell aplasia. Letter. Clin Exp Rheumatol 1996; 14:344-5.

6. Schattner A, Friedman J, Klepfish A, Berrebi A. Immune cytopenias as the presenting finding in primary Sjogren's syndrome. Qjm 2000;93:825-9.

7. Sugai S, Tachibana J, Shimizu S, Konda S. Thrombocytopenia in patients with Sjogren's syndrome. Arthritis Rheum 1989;32:234-5.

8. Khattri S, Barland P. Primary Sjogren's syndrome and autoimmune cytopenias: a relation often overlooked. Bull NYU
Hosp Jt Dis 2012;70:130-2.

9. Yu W, Qu W, Wang Z, et al. Sjogren's syndrome complicating pancytopenia, cerebral hemorrhage, and damage in nervous system: A case report and literature review. Medicine (Baltimore) 2017;96:e8542.

10. Klepfish A, Friedman J, Schechter Y, Schattner A. Autoimmune neutropenia, thrombocytopenia and Coombs positivity in a patient with primary Sjögren's syndrome. Rheumatology (Oxford) 2001;40:948-9.

11. Kamath V, Prabhakar B, Veena, Lachikarathman D. Sjogren's thrombocytopenia. J Assoc Physicians India 2011;59:114-5.

12. Komaru Y, Higuchi T, Koyamada R, et al. Primary Sjögren syndrome presenting with hemolytic anemia and pure red cell aplasia following delivery due to Coombs-negative autoimmune hemolytic anemia and hemophagocytosis. Intern Med 2013;52:2343-6.

13. Martínez VA, Leal CA, Moreno DC. Alteraciones hematológicas como manifestación inicial del síndrome de Sjögren primario. Rev Colomb Reumatol 2018;25:55-8.

14. Lamour A, Le Corre R, Pennec YL, et al. Heterogeneity of neutrophil antibodies in patients with primary Sjögren's syndrome. Blood 1995;86:3553-9.

15. Qing YF, Zhou JG, Yang MH. Clinical analysis of primary Sjogren's syndrome with hematological damages. Chin J Rheumatol 2009;13:117-9.

16. Schattner A, Shtalrid M, Berrebi A. Autoimmune haemolytic anemia preceding Sjogren's syndrome. J Rheumatol 1983;10:482-4. 